\title{
ABSTRAÇÕES EM GEOMETRIA: UMA ALTERNATIVA PARA ANÁLISE DO PENSAMENTO GEOMÉTRICO'1
}

\author{
ABSTRACTIONS IN GEOMETRY: AN ALTERNATIVE \\ FOR ANALYSIS OF GEOMETRIC THINKING
}

\author{
ANDRÉ PEREIRA DA COSTA*
}

\section{RESUMO}

Este artigo, de natureza teórica, tem por objetivo introduzir o conceito de abstração geométrica como uma alternativa para análise do pensamento geométrico de estudantes do ensino básico, a partir do estudo dos registros de representação semiótica no domínio da Geometria. Consideramos que essa forma de pensar em Matemática é a capacidade de compreender a natureza dos fenômenos e inferir sobre eles; identificar e perceber a importância da Geometria como uma ferramenta para entendimento do mundo físico e como um modelo matemático para compreensão do mundo teórico. As propriedades das abstrações geométricas indicam a existência de níveis de desenvolvimento do pensamento geométrico. Isso é possível verificar, pois as características se tornam mais sofisticadas à medida que avançamos as abstrações. Portanto, pensar geometricamente demanda a mobilização de, no mínimo, uma das seis abstrações geométricas aqui analisadas: a espacial, a perceptiva, a analítica, a descritiva, a dedutiva e a hipotética. Essas características emergem a partir da abstração geométrica espacial.

Palavras-chave: Abstração geométrica. Representação semiótica. Pensamento geométrico.

\section{ABSTRACT}

This paper, of theoretical nature, aims to introduce the concept of geometric abstraction as an alternative for the analysis of geometric thinking of elementary school students, based on the study of semiotic representation records in the field of geometry. We consider that this way of thinking in mathematics is the ability to understand the nature of phenomena and to infer about them; identify and realize the importance of geometry as a tool for understanding the physical world and as a mathematical model for understanding the theoretical world. The properties of geometric abstractions indicate the existence of levels of development of geometric thinking. This is possible to verify, therefore, the characteristics become more sophisticated as we advance the abstractions. Therefore, thinking geometrically requires the mobilization of at least one of the six geometric abstractions analyzed here: spatial, perceptual, analytical, descriptive, deductive and hypothetical. These characteristics emerge from the spatial geometric abstraction.

Keywords: Geometric abstraction. Semiotic representation. Geometrical thinking.

\footnotetext{
1 Trata-se de um recorte da tese de doutorado do autor (PEREIRA DA COSTA, 2019).

* Doutor em Educação Matemática e Tecnológica pela Universidade Federal de Pernambuco (UFPE). Professor da Universidade Federal do Oeste da Bahia (UFOB), Barreiras, Bahia, Brasil. E-mail: andre.costa@ufob.edu.br. Orcid: https://orcid.org/0000-0003-0303-8656
} 


\section{INTRODUÇÃO}

Este trabalho possui um caráter teórico, visto que tem por objetivo introduzir o conceito de abstração geométrica como uma alternativa para análise do pensamento geométrico de estudantes do ensino básico, a partir do estudo dos registros de representação semiótica no domínio da Geometria.

Duval (1995) destaca que as representações semióticas são fundamentais à atividade cognitiva do pensamento do ser humano, sendo, ainda, responsáveis por comunicar, isto é, deixar as representações perceptíveis e disponíveis às pessoas. Desse modo, essas representações exercem uma função indispensável na formação do pensamento em Matemática.

Segundo 0 autor, essa importância se justifica pelo fato de que os objetos matemáticos devem ser tratados a partir de um sistema de representação. Além disso, tais objetos não são visíveis, são produções da nossa cognição, logo, necessitam desses sistemas para sua designação.

Duval (1995) considera que a construção dos conhecimentos em Matemática está fortemente atrelada à variedade de registros de representação. No caso específico das representações semióticas, no campo matemático, existe uma ampla diversidade dessas representações, as quais Duval (1995) organizou em quatro grupos de registros: a língua natural (associações verbais e conceituais); as escritas algébricas e formais (sistemas de escritas numéricas, algébricas, simbólicas e cálculo); as representações gráficas (gráficos cartesianos); e figuras geométricas (planas ou em perspectivas).

Duval (1995) destaca duas operações cognitivas importantes na compreensão do funcionamento cognitivo, especificamente, no estudo dos objetos em Matemática: 0 tratamento e a conversão. Para 0 autor, o tratamento consiste em uma modificação que ocorre dentro de um mesmo registro, enquanto que a conversão é a mudança da representação de um objeto matemático para outra representação desse próprio objeto. Então, a partir dessas alterações, que possuem diferenças, podemos realizar uma análise refinada do ensino e da aprendizagem da Geometria.

Como indica o pesquisador, a passagem pelos vários registros de representação deve ser complementada com a coordenação desses registros durante a solução de uma atividade ou de um problema em sala de aula. Coordenar provoca reconhecer 0 objeto em Matemática nos diversos registros que os representam, além de compreender que tais registros se completam e manifestam atributos e propriedades matemáticas do objeto. Então, inicialmente, para compreender Matemática é necessário que o estudante coordene, no mínimo, dois registros de representação semiótica relacionados a um certo objeto.

Um importante itinerário para a compreensão de como 0 aluno aprende Geometria, sobretudo quando ele tem contato com as figuras geométricas, é por meio das apreensões geométricas, propostas por Duval (1995). Em nossa compreensão, elas consistem em um modelo de desenvolvimento do pensamento geométrico: apreensão perceptiva, apreensão sequencial, apreensão discursiva, apreensão operatória.

A apreensão perceptiva possibilita a identificação ou o reconhecimento, rapidamente, de uma forma (ou objeto) representada no plano ou no espaço. Epistemologicamente, tem o papel de identificar os objetos de duas ou de três dimensões. Tal tarefa é executada a partir de tratamentos de natureza cognitiva, realizados de modo automático, logo, sem consciência. Esse tipo de apreensão refere-se à primeira impressão visual e com a leitura dos formatos da figura em um cenário da Geometria.

A apreensão sequencial é marcada pela construção de uma figura geométrica ou ainda pela descrição dessa construção. Ela corresponde à ordem de como ocorre a produção da figura. Então, ela não 
depende somente das propriedades geométricas vinculadas à figura, mas de demandas de natureza técnica dos instrumentos empregados (software, compasso, régua, etc.).

A apreensão discursiva refere-se a uma hipótese, uma legenda ou a uma denominação. Ela está relacionada ao fato de que as propriedades geométricas representadas em um desenho não podem ser definidas por meio da percepção, logo, devem ser explicadas a partir das variáveis da figura geométrica. Segundo Duval (1995), essa justificativa é de ordem dedutiva.

A apreensão operatória é mobilizada quando 0 estudante opera sobre as figuras geométricas por meio de manipulação, composição, transformação, reconfiguração, comparação dos objetos voltados à Geometria para solucionar certa situação geométrica. Para Duval (1995), essa apreensão é mais sofisticada cognitivamente do que as demais apreensões, sendo alcançada por um estudante proficiente em Geometria.

É importante destacar que as apreensões não são isoladas, logo, é possível que na solução de um problema, um estudante utilize mais de uma das apreensões. Para tanto, essa conexão entre as apreensões será necessária para a compreensão da situação. Além disso, não há hierarquia entre as apreensões, mas sim uma subordinação, sendo que a apreensão perceptiva coordena esse processo.

Essa relevância da apreensão perceptiva fez Duval (2005) realizar a caracterização dos diferentes modos de olhar em Geometria, que consistem na classificação das formas de ver, de acordo com a função das figuras nas atividades geométricas propostas aos alunos: 0 olhar do botanista, 0 olhar do agrimensor, 0 olhar do construtor e 0 olhar do inventor.

Como indicam Moretti e Brand (2015), o olhar botanista é marcado pela identificação do contorno de formas, pela diferenciação de um triângulo de um quadrilátero ou de uma figura circular. 0 olhar agrimensor é caracterizado pelas medidas no terreno e pela transposição dessas medidas para o papel. 0 olhar do construtor é aquele que utiliza instrumentos (régua e compasso) na construção e toma consciência de que uma propriedade em Geometria não é somente um atributo visual. 0 olhar inventor na solução de um problema ocorre quando realiza modificações e operações na figura na busca de um percurso adequado de resolução.

Na próxima seção, discutiremos sobre as abstrações em Geometria com base em registros de representação semiótica.

\section{O DESENHO METODOLÓGICO}

Esta pesquisa possui uma abordagem qualitativa, visto que, conforme sinalizado por Triviños (1987), o estudo qualitativo tem por finalidade investigar e entender um fenômeno em sua especificidade. Além disso, no âmbito da Educação, esse fenômeno é chamado de fenômeno educacional.

Para elucidar as abstrações geométricas propostas neste artigo, foram considerados os dados produzidos em três estudos. No primeiro, cujos autores são Santos Costa, Allevato e Moura (2017), analisamos a produção de um grupo de estudantes do quinto ano do ensino fundamental, com idade média de 10 anos, acerca de um problema de orientação espacial. Conforme indicado pelos autores, o grupo era composto por 16 alunos, organizados em quatro subgrupos.

0 segundo estudo foi produzido por Leivas, Portella e Souza (2017). Nessa pesquisa, fizemos a análise da produção de três estudantes dos anos finais do ensino fundamental, referente a um problema sobre Geometria Hiperbólica. Segundo os autores da pesquisa, a idade dos alunos variava entre 12 e 14 anos. 
No terceiro estudo, retomamos alguns dados derivados de nossa tese de doutorado (PEREIRA DA COSTA, 2019), referente à produção de quatro estudantes, com idade entre 11 e 14 anos, que cursavam os anos finais do ensino fundamental e 0 ensino médio na época do estudo. Esses alunos responderam um problema sobre os quadriláteros notáveis.

Maiores detalhes sobre os itens analisados podem ser encontrados no próximo tópico deste texto ou nos próprios textos dos autores, os quais podem ser verificados nas referências deste artigo. É importante destacar que não fazemos parte da autoria dos dois primeiros estudos mencionados (SANTOS COSTA, ALLEVATO; MOURA, 2017; LEIVAS, PORTELLA; SOUZA, 2017).

Com isso, realizamos a análise dos dados apresentados, considerando como sustentação teórica a Teoria dos Registros de Representação Semiótica desenvolvida Duval (1995), sobretudo, com relação às operações cognitivas (tratamento e conversão). Para isso, focamos nas características do pensamento geométrico mobilizadas na resolução dos problemas propostos, conforme a tipologia de abstração geométrica proposta neste artigo.

\section{AS ABSTRAÇÕES EM GEOMETRIA}

No ensino de Matemática, a abstração não é um processo que se desenvolve apenas no estudo de processos dedutivos e de diferentes sistemas axiomáticos no ensino superior. Logo, pode ocorrer já a partir do contato com conceitos geométricos elementares no início da escolarização. Nessa direção, Nasser (2013, p. 892) sinaliza que:

a habilidade de abstração deve ser desenvolvida desde os primeiros anos de escolaridade. Os conceitos de número, reta e quadrado são exemplos de objetos matemáticos que dependem de uma abstração. Três processos contribuem para a abstração: representação, generalização e síntese. No caso dos números, por exemplo, é imprescindível que os alunos entendam a diferença de representação de um número natural e de um número racional: enquanto o número natural tem uma representação numérica única, um número racional representa uma classe de equivalência, com infinitos elementos, que são representações distintas para o mesmo número. Se esse conceito não for bem construído, os alunos não dominam o conceito de frações equivalentes, e essa dificuldade cria obstáculos para a aprendizagem de diversos conceitos, como porcentagem e escalas de ampliação ou redução (negrito nosso).

Nessa mesma linha de reflexão, Almouloud (2017, p. 29) afirma que a abstração em Geometria se inicia quando a criança interage com os objetos do mundo físico:

[...] a geometria começa com uma teoria baseada em objetos, pois inclui muitos atos de abstração empírica com foco em objetos, mas que não despreza, de forma alguma, a existência de processos. Os conceitos, em geometria, são decorrentes de atividades que envolvem a interação física com o mundo real e dependem, também, da sofisticação da linguagem. 0 objeto é o foco da atenção e, só mais tarde, a linguagem utilizada para a descrição permite que a mente construa objetos platônicos, como linhas "sem largura", por exemplo (negrito nosso). 
Segundo Dreyfus (2002), a abstração se refere profundamente à síntese e à generalização, mas necessita de certa energia mental pelos alunos, tendo em vista que se fundamenta na produção de estruturas cognitivas por meio de características e conexões estabelecidas entre os objetos de natureza geométrica, desconsiderando a visão sobre esse objeto.

Corroborando com esse pesquisador, autores como Klaiber, Souza, Silva e Savioli (2018) afirmam que esse processo demanda um pensamento matemático mais desenvolvido, porque, por exemplo, diante de um problema em Geometria, quando um estudante abstrai, isso significa que ele alcançou certo nível de pensamento geométrico, mais refinado do que o nível anterior.

Não há uma distinção nítida entre muitos dos processos de pensamento matemático elementar e avançado, embora a matemática avançada esteja mais focada nas abstrações de definição e dedução. Muitos dos processos a serem considerados já estão presentes em crianças que pensam em conceitos elementares de matemática, digamos número ou valor de lugar. Eles não são usados exclusivamente em matemática avançada, nem, na verdade, são usados exclusivamente em matemática. É possível pensar em tópicos matemáticos avançados de uma maneira elementar (por exemplo, muitos exercícios padrão em anéis ou grupos podem ser respondidos apenas conectando os números certos), e há um pensamento bastante avançado sobre tópicos elementares (veja alguns dos problemas nas olimpíadas de matemática). Uma característica distintiva entre o pensamento avançado e elementar é a complexidade e como ela é tratada (DREYFUS, 2002, p. 26, tradução nossa).

Conforme sinalizado por esse autor, a abstração pode ocorrer em diversos momentos educacionais, desde a escola básica até a universidade. 0 que a diferenciará é o foco que é dado em cada nível de escolaridade, bem como a natureza dos objetos geométricos em jogo.

Diante dessas circunstâncias, ou seja, nos fundamentando na ideia de abstração desenvolvida por Dreyfus (2002), Nasser (2013) e Almouloud (2017), em nossa compreensão, o pensamento geométrico é caracterizado por abstrações de natureza geométrica: abstração geométrica espacial, abstração geométrica perceptiva, abstração geométrica analítica, abstração geométrica descritiva, abstração geométrica dedutiva e abstração geométrica hipotética ou teórica. Ainda, neste artigo, sustentamos que no centro dessa caracterização está a abstração geométrica espacial, seguida das demais.

É importante destacar que esse processo não é tão estanque, pois a hierarquia entre essas abstrações geométricas só inicia de forma mais definida a partir da abstração geométrica perceptiva, isto é, da passagem dessa para a analítica, finalizando com a hipotética.

Desse modo, simultaneamente, um aluno que esteja matriculado nos anos iniciais do ensino fundamental pode atuar na perceptiva (ao analisar os quadriláteros a partir do aspecto global) e na espacial (ao estudar conceitos relacionados à orientação espacial).

Ao chegar nos anos finais do ensino fundamental, com 0 estudo dos quadriláteros notáveis, esse mesmo estudante pode avançar para a abstração geométrica analítica ou então para a descritiva. Todavia, também atua na espacial, simultaneamente. Isso ocorre, pois, os conceitos vivenciados nessa última abstração não focam os quadriláteros, mas sim orientação, direção e sentido no espaço.

0 mesmo pode ocorrer com um aluno que, ao estudar as Geometrias Não-Euclidianas, é capaz de realizar demonstrações a partir de diferentes sistemas axiomáticos. Logo, ele atua na abstração geométrica hipotética ou teórica, mas também trabalha na espacial, ao mesmo tempo. 
Podemos considerar que o pensamento geométrico é a capacidade mental de construir conhecimentos geométricos de aplicar de modo coerente os instrumentos geométricos ${ }^{2}$ na resolução de problemas. É a capacidade de compreender a natureza dos fenômenos e inferir sobre eles; identificar e perceber a importância da Geometria como uma ferramenta para entendimento do mundo físico e como um modelo matemático para compreensão do mundo teórico. Tudo isso é possível por meio de abstrações geométricas ${ }^{3}$. São essas abstrações que possibilitam o sujeito desenvolver essa forma de pensar em Matemática.

Visando uma melhor compreensão da estrutura de pensamento geométrico, elaboramos um esquema que apresenta como essas abstrações se articulam entre si, como ilustrado na Figura 1.

Figura 1 - Esquema das abstrações geométricas que caracterizam o pensamento geométrico.

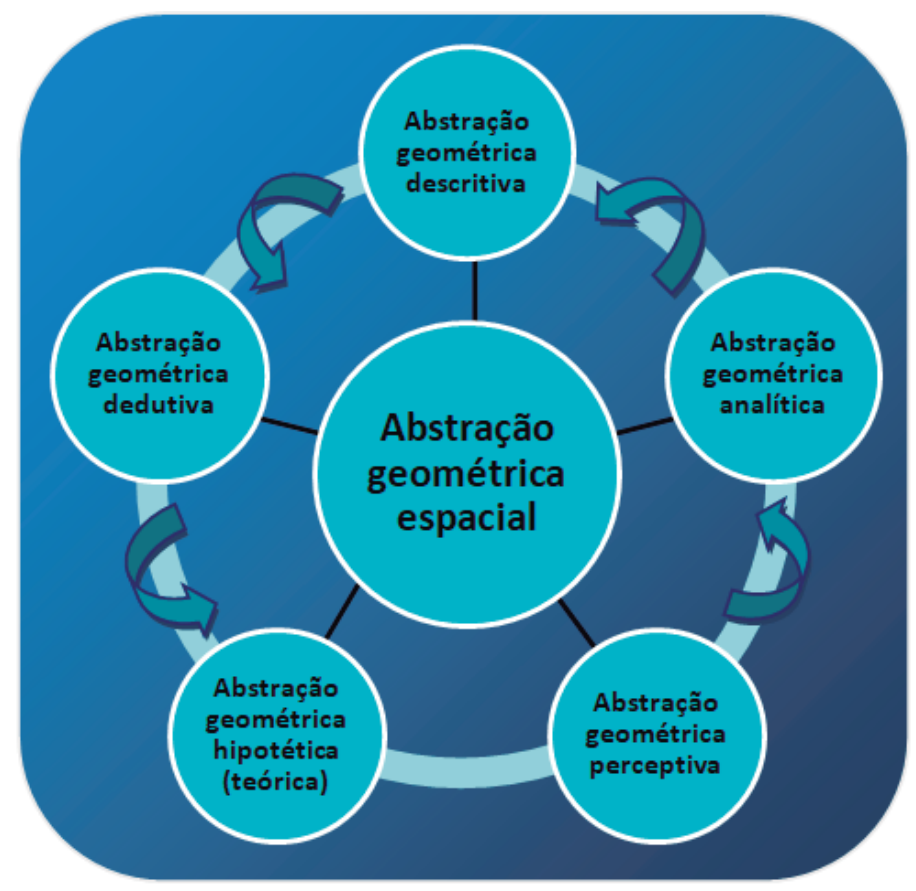

Fonte: Pereira da Costa (2019).

É importante destacar que a tipologia de abstrações geométricas é uma proposta de nossa pesquisa. Para isso, nos baseamos em Duval (1995), Pais (1996), Gravina (2001) e Leivas (2009). Por exemplo, para nomear a abstração geométrica perceptiva, utilizamos a palavra "perceptiva" da apreensão perceptiva de Duval (1995).

Para a abstração geométrica dedutiva, extraímos "dedutiva" do texto de Gravina (2001), em referência à Geometria Dedutiva. Na abstração geométrica hipotética ou teórica, usamos novamente "hipotética" de Gravina (2001), que discute sobre Geometria Hipotética, e a "teórica" utilizamos de Pais (1996), ao introduzir conhecimento geométrico teórico.

2 Estamos chamando de instrumentos geométricos, tanto os processos mentais utilizados para resolver problemas ou compreender um assunto em Geometria (THÉRĖSE, 2000), como também as ferramentas tecnológicas utilizadas nessas situações como régua, compasso, software de Geometria Dinâmica, etc (RÉGNIER, 2017).

3 Nesse artigo, consideramos que abstração geométrica é uma operação mental, por meio da qual somos conscientes de similaridades entre nossas experiências geométricas. 
Além disso, as abstrações geométricas do tipo dedutiva e hipotética estão incluídas no pensamento geométrico avançado, caracterizado pelo estudo de diferentes sistemas axiomáticos, como afirma Leivas (2009). As demais abstrações estão vinculadas ao pensamento geométrico elementar, marcado pelo contato com geometrias plana e espacial.

A abstração geométrica espacial é marcada pelo estudo (ou vivência) dos conceitos de orientação espacial, que também envolvem localização, orientação, deslocamento, etc. A orientação espacial pode ser entendida como 0 "pegar" a realidade na qual a criança habita e realiza seus movimentos. Esse termo tem um elemento intuitivo que se estabelece desde o seu nascimento (BREDA; SERRAZINA; MENEZES; SOUSA; OLIVEIRA, 2011). Nessa direção, Mendes e Delgado (2008, p. 10) destacam que:

desde muito cedo, as crianças começam a desenvolver alguns conceitos geométricos e o raciocínio espacial. Ainda bebês, não só revelam curiosidade em "olhar" 0 espaço que as rodeia, como, também, interagem com ele, tentando, por exemplo, alcançar, atirar e empurrar objetos. Durante estas experiências, vão processando ideias sobre as formas e o espaço. Estas ideias, ainda muito rudimentares, constituem já a base para o conhecimento geométrico e o raciocínio espacial que deverá ser desenvolvido ao longo dos anos seguintes.

Ao se movimentarem em sua realidade natural e ao interagirem com os objetos, com pessoas ou lugares, as crianças pequenas constroem várias noções espaciais, logo, suas primeiras experiências são de natureza espacial. Além disso, as primeiras noções de orientação espacial podem ainda começar a partir do seu próprio corpo, pela lateralização. A orientação espacial se desenvolve por meio da vivência e da atividade experimental em tarefas espaciais concretas. Logo, ao serem introduzidas na escola, o professor deve considerar que as crianças apresentam várias noções intuitivas sobre o espaço (PIRES; CURl; CAMPOS, 2000).

A orientação espacial ocorre, por exemplo, quando uma criança é consciente de suas relações com outros objetos em termos de posição, direção e distância. Ela também abrange a tarefa de organizar o espaço, de maneira que os objetos estejam colocados de modo adequado seja para trabalho como para diversão, ou até mesmo para combater a poluição visual (SANTOS COSTA; ALLEVATO; MOURA, 2017).

Para compreender um pouco melhor sobre como é mobilizada a abstração geométrica espacial, analisaremos a resposta de um grupo de alunos do quinto ano do ensino fundamental (com idade média de 10 anos) em um problema que explorou o conceito de orientação espacial.

Tal atividade foi extraída da pesquisa de Santos Costa, Allevato e Moura (2017), sendo inicialmente produzida por Barbosa (2011). É importante destacar que não somos autores desse estudo, dessa forma, faremos uma análise dos dados apresentados pelos supracitados pesquisadores.

Conforme os autores da investigação, o objetivo da atividade era analisar como esses estudantes interpretavam e esboçavam caminhos por meio de mapas, com abordagem dos conceitos de dimensão e direção. Então, as crianças deveriam (re)construir o percurso do carrinho por meio dos mapas e das orientações fornecidas, conforme ilustrado na Figura 2.

Além disso, como apresentando na Figura 3 e sinalizado pelos autores do estudo, os alunos interpretaram e esboçaram corretamente 0 itinerário do carrinho a partir dos mapas e das orientações fornecidas. Logo, mobilizaram o conceito de orientação espacial, especificamente as noções de direção e dimensão. 
Nessa situação, em nosso entendimento, as crianças mobilizaram a abstração geométrica espacial na solução da atividade proposta. Além disso, a Geometria é vista em seu caráter prático, voltado para o cotidiano desses estudantes.

Analisando o primeiro momento da atividade, isto é, a construção do percurso feito pelo carrinho, percebemos que o grupo de alunos não realizou tratamento conforme indica Duval (2005). Então, não houve transformações no interior do registro "mapa", ou seja, os alunos apenas reproduziram o caminho disponibilizado. Também, nesse momento não houve conversão para a representação gráfica.

Figura 2 - Extratos dos mapas utilizados na pesquisa de Santos Costa, Allevato e Moura (2017)
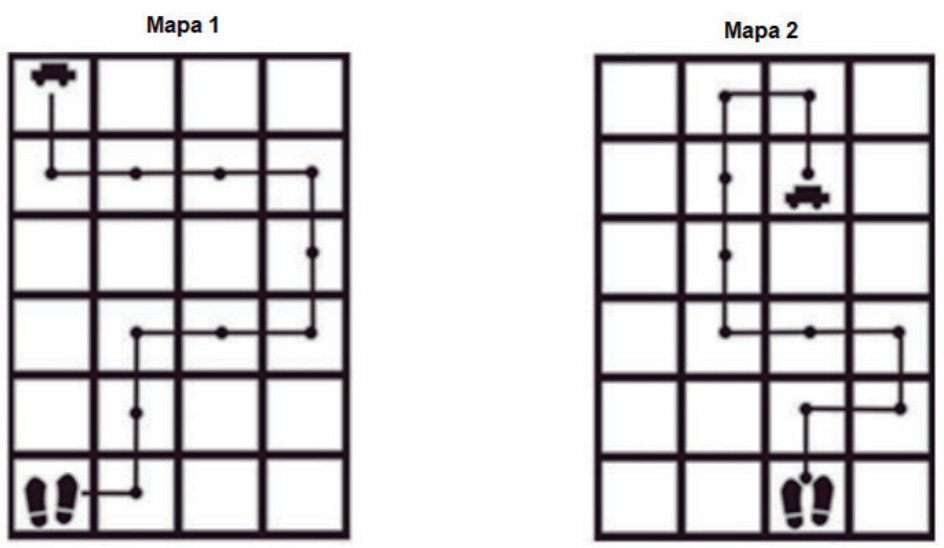

Fonte: Santos Costa, Allevato e Moura (2017, p. 23)

Na segunda etapa da atividade, ao escreverem na folha o percurso do carrinho, tendo por base Duval (1995), os discentes realizaram conversão (de volta), logo transformaram a representação gráfica (mapa) em outra representação (língua natural), mas eles não fizeram tratamento.

Figura 3 - Extrato da resposta de um grupo de alunos à atividade enunciada por Santos Costa, Allevato e Moura (2017)
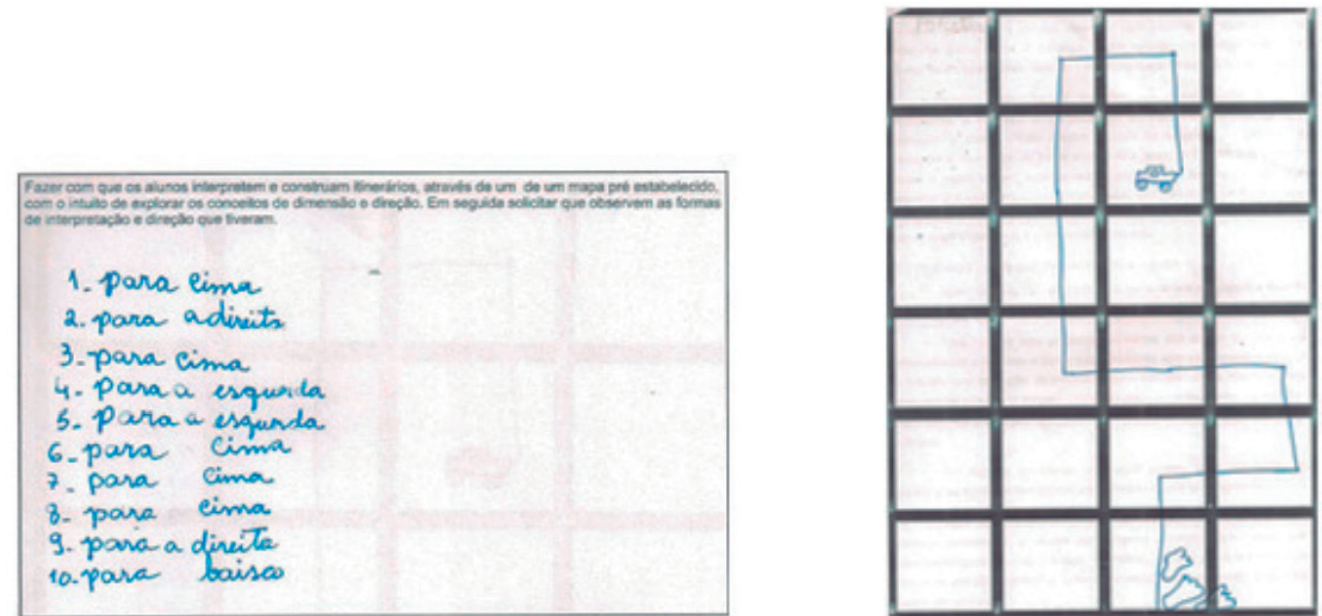

Fonte: Santos Costa, Allevato e Moura (2017, p. 25) 
Conforme Duval (1995), ao longo da atividade, os alunos mobilizaram a apreensão perceptiva, pois identificaram um objeto (carrinho) num plano e, por isso, apresentaram olhares botanistas. Como reproduziram o desenho de um carrinho, que representa um objeto, esses estudantes também atuaram na apreensão sequencial.

Além disso, com relação à linguagem utilizada, em nosso entendimento, esses alunos atuaram no nível de linguagem cotidiana, empregando termos como "cima", "baixo", "direita" e "esquerda" que, mesmo sendo expressões aplicadas à sua realidade cotidiana, também fazem referência à direção, que é uma noção vinculada ao conceito de orientação espacial. Essa linguagem é característica da abstração geométrica espacial.

A abstração geométrica perceptiva é caracterizada por sensações perceptivas e visuais. Dessa forma, "as primeiras idealizações espontâneas de qualquer criança se apóiam em qualidades comuns que certos objetos apresentam e são simplesmente impressões visuais associadas a determinados nomes" (GRAVINA, 2001, p. 51).

Nessa abstração geométrica, uma figura é analisada como um todo, destituída de elementos e de propriedades. As falas são carregadas de experiências unicamente perceptivas e visuais; então, as crianças (ou os adultos) realizam classificações e nomeações de formas geométricas ao abstrair aspectos perceptivos dos objetos geométricos representados, logo, não fazem referência às suas propriedades.

Uma pessoa que esteja atuando nessa abstração, ao ser questionada por que uma figura é um retângulo, dirá que "é um retângulo porque é como uma janela ou uma porta". Isso ocorre, pois, as representações dos objetos geométricos são compreendidas como objetos físicos, pertencentes à sua realidade e não à Matemática. Logo, a Geometria vivenciada é de caráter prático, da vida cotidiana, não sendo compreendida como um modelo teórico matemático.

Nessa abstração, é possível encontrar pessoas que percebem formas geométricas somente a partir de um subconjunto das características visuais, pois ainda não conseguem formar imagens visuais. Desse modo, não realizam a identificação de várias formas geométricas comuns, distinguindo apenas as figuras que apresentam curvas das figuras que possuem retas; todavia, isso não ocorre entre figuras do mesmo grupo. Por exemplo, conseguem diferenciar uma circunferência de um quadrado, contudo não distinguem um quadrado de um retângulo.

Para compreender o que significa essa abstração e como se manifesta na solução de uma atividade sobre os quadriláteros notáveis, analisaremos a resposta de um estudante (com 11 anos de idade) à questão a seguir. É importante salientar que os dados analisados para esse tipo de abstração fazem parte de uma pesquisa ${ }^{4}$ que realizamos com alunos dos anos finais do ensino fundamental.

Q01: Você desenhou um retângulo. Seu colega desenhou uma figura de quatro lados que não é um retângulo. Nos espaços abaixo, desenhe como poderia ser a sua figura e a figura de seu colega

4 Essa pesquisa trata-se de um estudo piloto que realizamos com 30 alunos de uma escola pública de Recife. Os dados desse estudo não foram analisados e nem publicados, desse modo, estamos realizando uma análise deles nesse artigo para ilustrar a tipologia de abstrações geométricas. 
Figura 4 - Resposta de um aluno à questão proposta

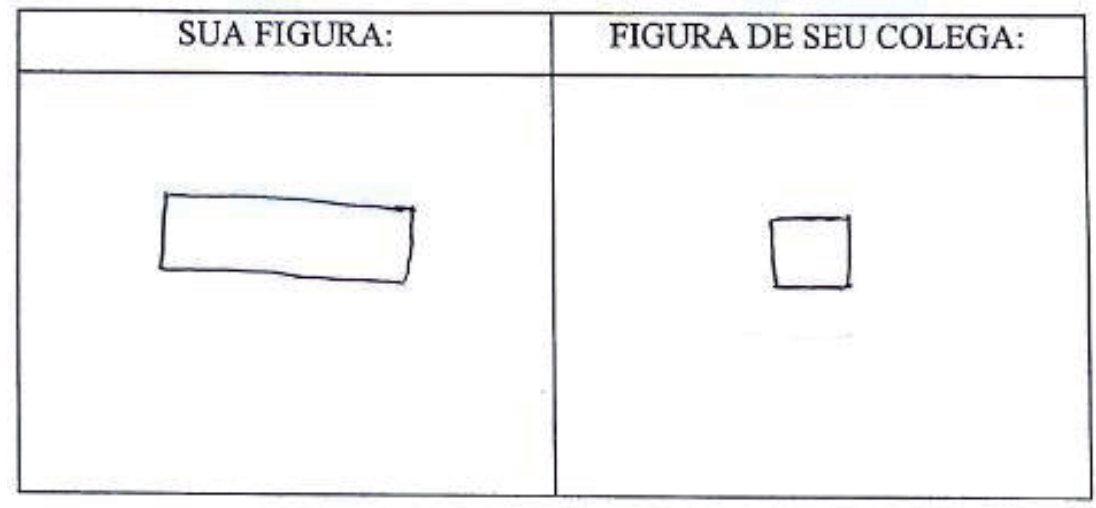

Fonte: Pereira da Costa (2019).

Nessa questão, como ilustrado na Figura 4, verificamos que 0 aluno conseguiu identificar formas geométricas e reproduzi-las a partir da nomenclatura. Então, houve uma associação entre a palavra "retângulo" e o desenho correspondente, isto é, com base em Duval (1995), efetuou uma conversão (de ida) entre a língua natural (retângulo) e a figura geométrica (representada pelo desenho).

No entanto, como notado na produção, ele não fez uso adequado do conceito, dos elementos e das propriedades do retângulo. Pois, ao desenhar um quadrado (como não sendo retângulo) na figura do seu colega, demonstra ter considerado apenas a aparência global da figura, conforme podemos verificar na entrevista realizada pelo pesquisador com 0 aluno.

Dessa forma, ele não fez conversão referente ao segundo desenho, conforme a teoria de Duval (1995). Como produziu desenhos referentes às representações de figuras geométricas, 0 aluno mobilizou a apreensão sequencial. A seguir, apresentamos um recorte da entrevista que realizamos com esse aluno.

Pesquisador: Que figura é essa que você desenhou? (apontando para o campo "Sua Figura”).

Aluno: É um retângulo.

Pesquisador: Por que ela é um retângulo?

Aluno: Porque tem dois lados mais compridos e dois lados menos compridos.

Pesquisador: Como se chama a figura do seu colega? (apontando para o campo "Figura de seu colega")

Aluno: Quadrado.

Pesquisador: Por que ela é um quadrado?

Aluno: Porque tem os lados pequenos.

Pesquisador: Como assim? Lados pequenos?

Aluno: Ela tem todos os lados pequenos e acho que são do mesmo tamanho.

Pesquisador: A sua figura é um quadrado?

Aluno: Não.

Pesquisador: Por que?

Aluno: Porque o retângulo não tem lados pequenos, ele tem dois grandes e dois pequenos.

E para ser quadrado tem que ter todos os lados pequenos.

Pesquisador: A figura do seu colega é um retângulo?

Aluno: Não, pois o quadrado não tem dois lados compridos como o retângulo.

Pesquisador: Eu não entendi. Podes me explicar novamente?

Aluno: Deixa eu pensar um pouco... O quadrado é como se fosse um dado e o retângulo parece uma porta.

E porta e dado são coisas diferentes, então, o quadrado e o retângulo não são iguais. Eles não se parecem. 
Pelo diálogo, foi possível notarmos que o entrevistado, ao justificar o motivo de sua figura ser um retângulo, fez uso de definição visual, ou seja, disse exatamente 0 que vê na figura (dois lados maiores e dois lados menores). 0 mesmo fenômeno pode ser verificado na explicação do quadrado.

0 estudante fez uso apenas do aspecto perceptivo, olhando as figuras desenhadas de forma global, desprezando seus conceitos, seus elementos constituintes e suas propriedades. Logo, considerando Duval (1995), atuou na apreensão perceptiva com olhar botanista.

Além disso, ao dizer que o "quadrado é como se fosse um dado" e o "retângulo parece uma porta", fica claro que os objetos quadrado e retângulo não são analisados geometricamente, mas como se fossem objetos do mundo real, do cotidiano do aluno. Dessa forma, a Geometria é vista como prática cotidiana e não como um modelo teórico da Matemática.

Também verificamos que não houve conversão (de volta) de acordo com Duval (1995), pois, mesmo fazendo uso da língua natural, ele não fez articulação das variáveis dos objetos geométricos evidenciados na atividade. Não observamos, ainda, a realização de tratamento.

Percebemos, ainda, que 0 aluno faz uso de certo vocabulário geométrico, todavia ainda é bastante influenciado pela linguagem cotidiana com caráter perceptivo. Portanto, diante de todas as evidências, esse aluno mobilizou a abstração geométrica perceptiva na resolução da atividade. A ruptura com esse tipo de abstração é assinalada pela sofisticação das idealizações pelos alunos, isto é, os registros perceptivos transformam-se em objetos geométricos a partir da conceituação das propriedades que os caracterizam (GRAVINA, 2001).

A abstração geométrica analítica é caracterizada pela análise das figuras geométricas conforme seus elementos constituintes e suas propriedades, todavia, não é possível estabelecer relações de inferências entre essas propriedades. Além disso, é possível verificar definições dessas figuras, mas de forma bastante ampla e sem sentido para o sujeito.

Ao manipular figuras geométricas por meio de dobraduras e recortes, um retângulo é considerado como uma forma que apresenta quatro ângulos retos, diagonais congruentes, dois lados curtos e dois lados longos, entre outros aspectos, apontando, assim, uma ampla relação de propriedades.

Veja que as definições não são econômicas, mas elas não foram compreendidas com significado, caso contrário, um quadrado seria reconhecido como um retângulo. Por exemplo, a seguinte relação ainda não é evidenciada nesse tipo de abstração geométrica: "se quatro ângulos são retos, então, obrigatoriamente os lados opostos são congruentes".

Ainda nesse tipo de abstração, também é possível verificar pessoas que consideram apenas a definição das figuras geométricas em seu processo de reconhecimento. Contudo, ainda não conseguem identificar essas figuras como detentoras de características específicas.

Para um melhor entendimento da abstração geométrica analítica e como se revela na solução da mesma atividade analisada anteriormente (questão Q01), ilustramos a produção de uma estudante (com 14 anos de idade), participante de outra pesquisa, a qual realizamos com alunos dos anos finais do ensino fundamental. 
Figura 5 - Resposta da segunda aluna à questão proposta.

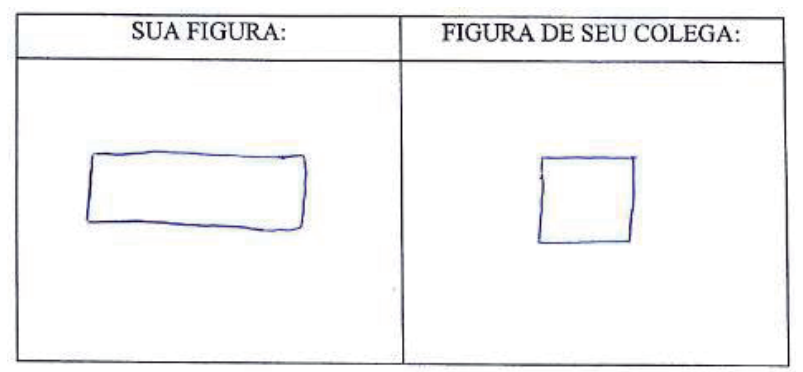

Fonte: Pereira da Costa (2019).

Observamos, pela Figura 5, que, assim como na produção da estudante analisado anteriormente, a aluna reconheceu formas geométricas e conseguiu reproduzi-las por meio da nomenclatura. Também relacionou à palavra "retângulo" o desenho correlato, ou seja, com base em Duval (1995), fez conversão (de ida) entre a língua natural e a figura geométrica.

Contudo, não houve compreensão adequada da definição, pois, se houvesse, ela não teria considerado o quadrado na figura do seu colega, já que também é retângulo. Ela não realizou conversão (de ida) na segunda produção. Isso também é notado na entrevista realizada pelo pesquisador (autor do artigo) com a estudante. Por ter construído um desenho que representa uma figura geométrica, essa aluna mobilizou a apreensão sequencial.

Pela conversa construída entre o pesquisador e a aluna, percebemos que, ao explicar a razão de seu desenho representar um retângulo, ela apresentou uma ampla lista de propriedades, não economizando, assim, para mostrar uma definição relacionada à figura geométrica. Isso também foi notado na justificativa do quadrado.

Pesquisador: Qual o nome dessa figura que você desenhou aí? (apontando para "Sua Figura”).

Aluna: Retângulo.

Pesquisador: Por que ela é um retângulo?

Aluna: Porque ela tem lados opostos paralelos e iguais, os ângulos todos são retos, as diagonais têm o mesmo tamanho, e também tem dois lados longos e dois lados curtos.

Pesquisador: Que figura é essa que você fez para seu colega? (apontando para o campo "Figura de seu colega")

Aluna: É um quadrado.

Pesquisador: Por que ela é um quadrado?

Aluna: Porque os ângulos são de 90, os lados são opostos, paralelos e iguais e as diagonais são congruentes.

Pesquisador: Como assim? Essas características que você mencionou não são do retângulo?

Aluna: São dos dois, mas o quadrado tem lados curtos e o retângulo não.

Pesquisador: Então, a sua figura é um quadrado?

Aluna: Não.

Pesquisador: Por que?

Aluna: Porque o retângulo tem dois lados longos e dois lados curtos e o quadrado tem todos os lados curtos.

Pesquisador: A figura do seu colega é um retângulo?

Aluna: Não, é só quadrado, pois tem todos os lados curtos.

Pesquisador: Agora estou confuso. Quando a figura é retângulo e quando ela é quadrado? Uma figura não pode ser os dois ao mesmo tempo?

Aluna: Não, não pode... O retângulo e o quadrado apresentam algumas coisas iguais: os ângulos são de 90, as diagonais são iguais, se eu pegar uma régua fica mais fácil de perceber... os lados também são opostos e iguais... mas o quadrado não pode ser retângulo e o retângulo não pode ser quadrado... mas se eu aumentar o tamanho de dois lados do quadrado, ele vira um retângulo... e se eu reduzir os lados maiores do retângulo, deixando com o mesmo tamanho dos outros lados, então ele é quadrado. Tem que acontecer isso para retângulo ser quadrado e quadrado ser retângulo. Entendeu? 
Mesmo usando uma ampla lista de propriedades, todavia, a definição de retângulo não foi construída com significado, caso contrário, a estudante identificaria 0 quadrado como retângulo. Então, de acordo com Duval (1995), ela não fez uso consistente da apreensão discursiva, sendo bastante influenciada pela apreensão perceptiva com olhar botanista, marcado, assim, a subordinação da segunda apreensão pela primeira.

Além disso, não realizou conversão (de volta), pois mesmo fazendo uso de várias propriedades das figuras geométricas, não fez articulação das variáveis dos objetos geométricos evidenciados na atividade, ou seja, não houve coordenação. Não observamos, ainda, a realização de tratamento.

Também, ao mencionar que "o retângulo tem dois lados longos e dois lados curtos e o quadrado tem todos os lados curtos", a participante também apresenta uma definição visual, isto é, dizendo como são as figuras geométricas exatamente como as vê. Então, na abstração geométrica analítica podemos observar os dois tipos de definição: definição visual e definição com base nas propriedades, mas sem 0 estabelecimento de relações entre as propriedades.

Notamos, ainda, que essa estudante apresentou um vocabulário geométrico mais denso em relação à abstração analisada anteriormente, isto é, com mais expressões típicas da Geometria. Contudo, esse vocabulário ainda é influenciado pela linguagem cotidiana perceptiva. Nessa direção, mobilizou a abstração geométrica analítica ao resolver a questão.

A abstração geométrica descritiva é marcada pelo estabelecimento de relações de implicação entre propriedades dos objetos geométricos, mas sem 0 uso de argumentação dedutiva na justificativa desse estabelecimento. Nessa abstração geométrica, a pessoa apresenta definições aos objetos geométricos com significado, por isso, conseguindo reconhecer o quadrado como retângulo e losango ao mesmo tempo. Dessa forma, as inclusões de classe são desenvolvidas.

Uma pessoa, ao ser perguntada pelo motivo de uma figura ser um retângulo, responderá que "é um paralelogramo que tem ângulos internos retos". Também dirá que um quadrado é um retângulo, pois esses dois quadriláteros apresentam propriedades iguais.

Para uma melhor compreensão dessa característica do pensamento geométrico e bem como ele se manifesta na resolução de uma questão sobre os quadriláteros, retornemos ao item analisado anteriormente (Q01), mas com a produção de um terceiro estudante (com 13 anos de idade), partícipe de um estudo que realizamos com alunos dos anos finais do ensino fundamental.

Figura 6 - Resposta do terceiro aluno à questão proposta

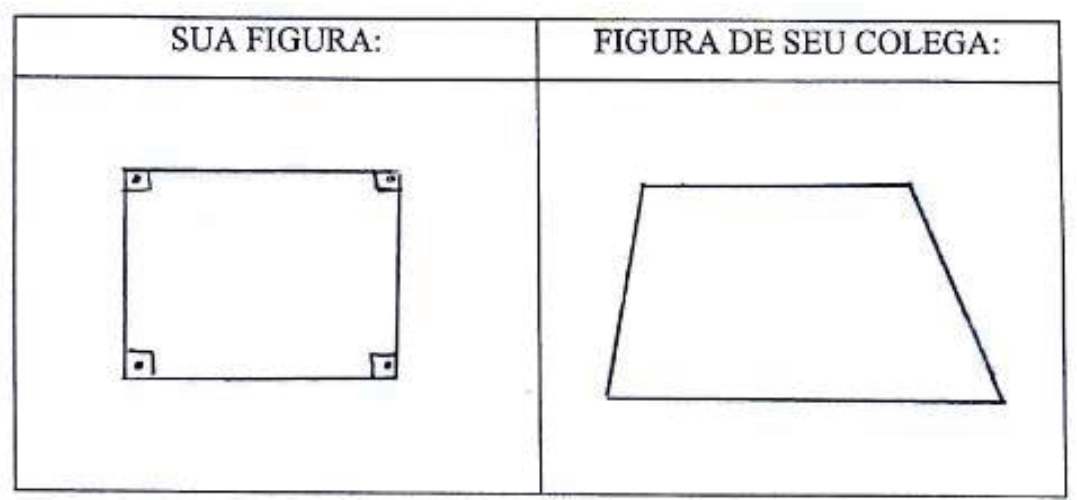

Fonte: Pereira da Costa (2019). 
Nessa atividade, analisamos que 0 estudante reconheceu formas geométricas com base na nomenclatura. Também, segundo a teoria de Duval (1995), ocorreu conversão (de ida) correta entre a palavra "retângulo" e o desenho correspondente, e entre a palavra "não retângulo" com o desenho do trapézio. Aqui evidenciamos a presença da apreensão sequencial, já que o participante fez construções de figuras geométricas.

Além disso, pelas marcações deixadas na folha, o aluno utilizou as medidas dos ângulos internos nas justificativas, mobilizando assim o olhar agrimensor, como pode ainda ser verificado na entrevista do pesquisador com o participante do estudo.

Pesquisador: Que figura é essa que você desenhou? (apontando para o campo "Sua Figura").
Aluno: É um retângulo.
Pesquisador: Por que ela é um retângulo?
Aluno: Porque é todo paralelogramo que tem ângulos internos retos.
Pesquisador: Como se chama a figura do seu colega? (apontando para o campo "Figura de seu colega")
Aluno: Trapézio.
Pesquisador: Por que ela é um trapézio?
Aluno: Porque é um quadrilátero que possui somente um único par de lados opostos paralelos.
Pesquisador: O retângulo que você desenhou é um quadrilátero?
Aluno: Sim, pois ele é convexo e possui dois lados opostos paralelos.
Pesquisador: O retângulo pode ser trapézio? E o trapézio pode ser retângulo?
Aluno: Não.
Pesquisador: Por que?
Aluno: Porque o retângulo é paralelogramo, tem dois pares de lados paralelos opostos. Os trapézios não são paralelogra-
mos, pois têm somente um único par de lados paralelos.
Pesquisador: A figura do seu colega é um quadrado?
Aluno: Não, pois o quadrado é um paralelogramo que é retângulo e losango ao mesmo tempo.
Pesquisador: Eu não entendi. Podes me explicar novamente?
Aluno: Veja só... o quadrado tem dois lados opostos paralelos, os ângulos são retos e as diagonais são iguais e se
cruzam no meio. Essas mesmas características ocorrem com os losangos e com os retângulos... a diferença é que alguns
losangos (os oblíquos) podem ter as diagonais não congruentes, e para ser losango só é necessário que a figura tenha to-
dos os lados iguais... isso ocorre com o quadrado, então ele é losango... No caso do retângulo, alguns retângulos podem
apresentar dois pares de lados maiores, e para ser retângulo a figura tem que ter os ângulos iguais... isso ocorre com o
quadrado, logo ele é retângulo. Então, o quadrado é losango e retângulo ao mesmo tempo, além de ser paralelogramo. 0
trapézio é de outro grupo dos quadriláteros, não é paralelogramo...

A partir da conversa entre o pesquisador e 0 estudante, evidenciamos que 0 aluno, ao explicar o motivo das figuras serem retângulo e trapézio, respectivamente, fez uso de definições e de várias propriedades. As definições foram compreendidas com significado, pois 0 discente concluiu que 0 quadrado é um paralelogramo que é losango e retângulo ao mesmo tempo e, ainda, que o trapézio não pertence à família dos paralelogramos.

Assim, conforme Duval (1995), o aluno realizou a conversão (de volta) da figura geométrica para a língua natural, logo, fez coordenação. Estabeleceu adequadamente relações entre as propriedades das figuras, desenvolvendo, assim, inclusão de classe, mobilizando a apreensão discursiva com olhar construtor, pois tomou consciência de que as propriedades das figuras geométricas não são de natureza perceptiva. Nesse contexto, o aluno atuou na abstração geométrica descritiva na resolução da atividade. Percebemos, ainda, uma riqueza no vocabulário geométrico do estudante, marcado por uma linguagem formal de cunho descritivo. 
A abstração geométrica dedutiva se caracteriza pelo estudo (ou vivência) de provas, demonstrações, argumentações e conjecturas de natureza tanto intuitiva como dedutiva. Assim, uma demonstração é compreendida e construída com significado. Além disso, a Geometria passa a ser vista como um modelo teórico matemático, formado por axiomas e teoremas.

Para um entendimento mais adequado dessa abstração geométrica, retomemos novamente a questão sobre quadriláteros notáveis já discutida aqui (Q01), mas com a produção de uma quarta aluna (com 14 anos de idade), participante de uma pesquisa que realizamos com alunos dos anos finais do ensino fundamental.

Nesse item, notamos que a aluna não apresentou dificuldades para identificar formas geométricas a partir da nomenclatura. Segundo a teoria de Duval (1995), mobilizando a apreensão sequencial, ela converteu (conversão de ida) corretamente a palavra "retângulo" e 0 desenho correlato e ainda com a palavra "não retângulo" e 0 desenho que representa o trapezoide.

Ainda, pelos registros deixados na folha de resposta, a estudante considerou as medidas dos comprimentos dos lados e as medidas das aberturas dos ângulos internos como forma de diferenciar as duas figuras geométricas, características do olhar agrimensor. Tal fato pode ser evidenciado na entrevista do pesquisador (autor desse artigo) com essa discente.

Figura 7 - Resposta da quarta aluna à questão proposta.

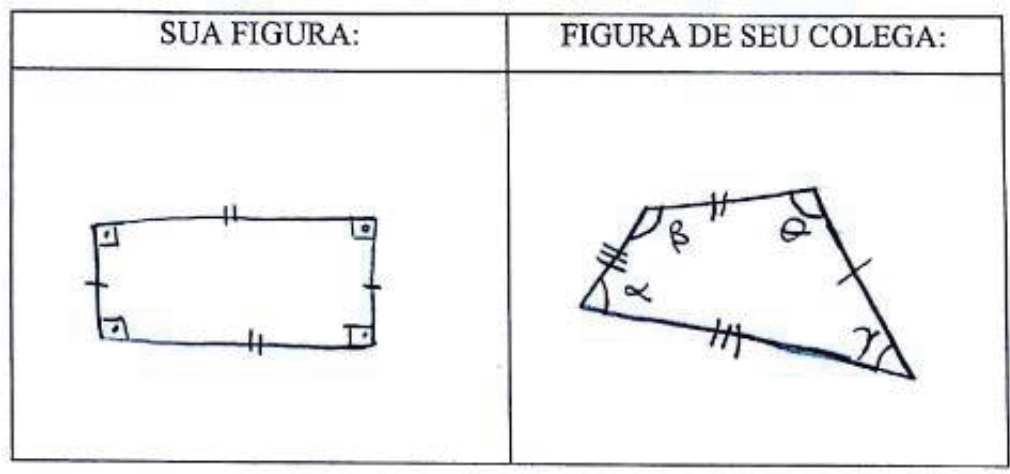

Fonte: Pereira da Costa (2019).

Com base no diálogo desenvolvido, notamos que a aluna tentou provar intuitivamente que um retângulo é um paralelogramo, a partir da decomposição de figuras geométricas e de argumentos e explicações. Na verdade, essa estudante realizou outra demonstração, isto é, ela mostrou que as áreas dos dois quadriláteros (retângulo e paralelogramo) são equivalentes. Mesmo não conseguindo provar que um retângulo é um paralelogramo por meio de uma demonstração, a aluna fez uma importante comprovação, de que a área da figura não foi alterada com a modificação. Na escola básica, muitos alunos têm dificuldades em compreender essa relação. 


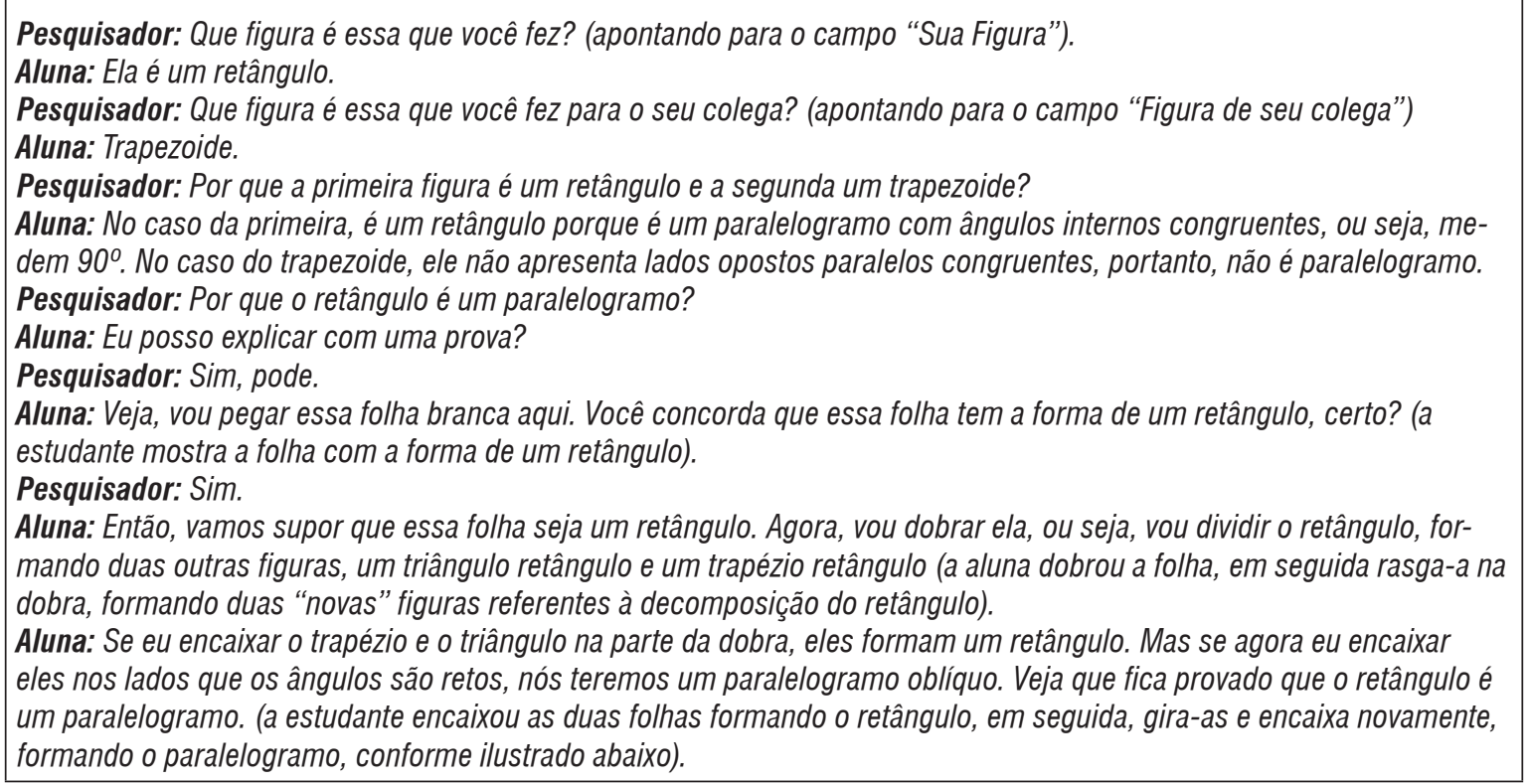

De acordo com Duval (1995), aqui evidenciamos a mobilização das apreensões operatória, com ênfase na modificação figural mereológica (marcada pela transformação de uma figura geométrica em outras figuras), e discursiva (caracterizada pela explicação das propriedades geométricas) com olhar de um inventor.

Além disso, ficou evidente que os conceitos referentes aos quadriláteros foram construídos adequadamente pela estudante, com significado de compreensão. Então, fez a conversão (de volta) entre a figura geométrica e a língua natural, dessa forma, ocorrendo coordenação. Nesse cenário, ela atuou na abstração geométrica dedutiva na solução do item. 0 vocabulário geométrico da discente é caracterizado por uma linguagem formal argumentativa dedutiva. Por fim, ao decompor a figura, a estudante realizou o tratamento, ou seja, fez transformações dentro do próprio registro de representação semiótica.

A abstração geométrica hipotética (ou teórica) é marcada pelo estudo (ou vivência) com diferentes geometrias, sobretudo, as chamadas Geometrias Não-Euclidianas, logo, a pessoa, nessa abstração, caminha por teorias axiomáticas, além de utilizar uma linguagem formal axiomática.

Para uma melhor compreensão desse tipo de abstração geométrica, vamos considerar a produção de um grupo formado por três alunos do ensino fundamental (12-14 anos de idade) a um problema sobre Geometria Hiperbólica. Esse problema foi extraído da pesquisa desenvolvida por Leivas, Portella e Souza (2017). É importante destacar que não fizemos parte da autoria desse estudo, logo, realizamos uma análise dos dados apresentados pelos pesquisadores supracitados.

De acordo com os autores, o objetivo proposto era produzir o ponto de inversão a uma circunferência, por um ponto fora dela. Dessa forma, com o uso do GeoGebra, um dos alunos fez o estudo da inversão de pontos relacionados à circunferência. Isso foi fundamental para a compreensão das h-retas (retas no Plano de Poincaré, que é formado a partir da região aberta definida pela circunferência). 0 problema era o seguinte: 
Construa o ponto de inversão a uma circunferência, por um ponto fora dela.

Figura 8 - Extrato da resposta de um aluno à atividade enunciada por Leivas, Portella e Souza (2017)

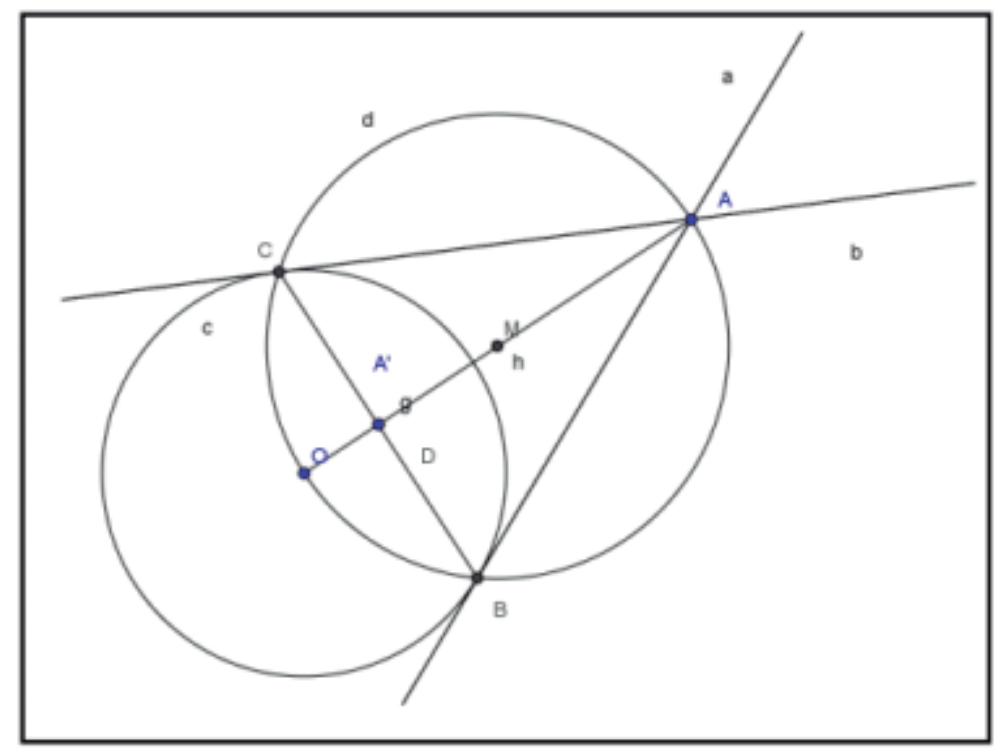

Fonte: Leivas, Portella e Souza (2017, p. 216)

Pela Figura 8, o ponto A, fora da circunferência, apresenta o ponto de inversão D. Conforme analisaram os autores, essa produção é interessante à elaboração das h-retas no modelo, que são formadas pelos arcos de curvas que penetram de forma ortogonal na circunferência limítrofe do disco.

Por ter realizado essa produção, o discente mobilizou a apreensão sequencial. Também, com base em Duval (1995), ocorreu conversão (de ida) entre a língua natural (ponto de inversão de uma circunferência) e a figura geométrica (representada pelo desenho no GeoGebra). Além disso, a compreensão da lógica do software possibilitou que eles construíssem novas ferramentas que foram incorporadas ao GeoGebra, sobretudo, relacionadas à produção do Disco de Poincaré, como ilustrado na Figura 9. Com essa atividade, os estudantes perceberam que existem outras geometrias. 
Figura 9 - Extrato da resposta de um aluno à atividade enunciada por Leivas, Portella e Souza (2017)

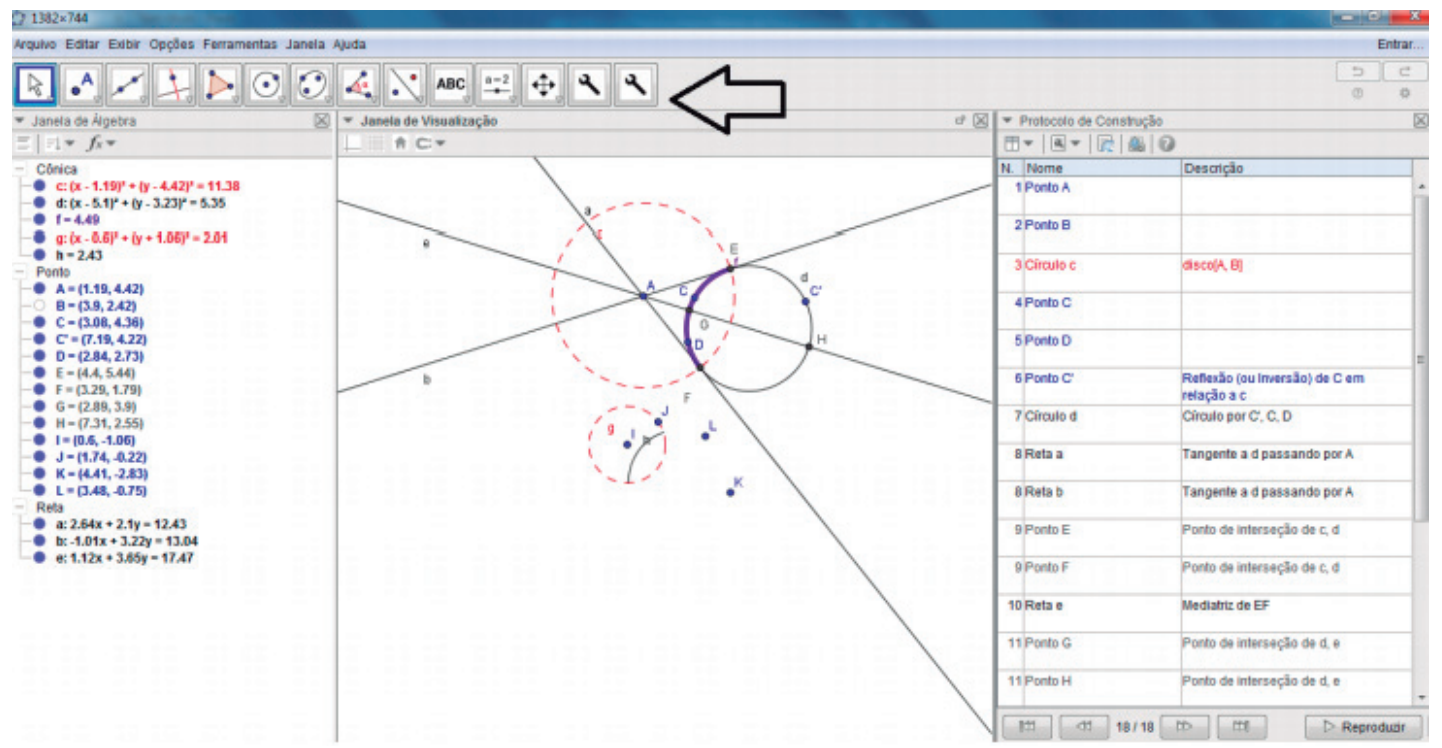

Fonte: Leivas, Portella e Souza (2017, p. 216)

Pela Figura 9, e pela descrição dos autores, podemos observar que os estudantes fizeram 0 tratamento da figura geométrica, isto é, realizaram transformações dentro do próprio registro. Eles realizaram várias conversões, da língua natural (enunciado do problema) para a figura geométrica (desenho na Janela Visualização do GeoGebra), e desta para as escritas algébricas (equações das circunferências na Janela de Álgebra do software).

Desse modo, com base em Duval (1995), houve coordenação. É notório que os estudantes têm um olhar do construtor (por utilizar o GeoGebra como instrumento para suas construções) e do inventor (por ter realizado modificações no próprio programa, com a inclusão da ferramenta "Disco de Poincaré").

Além disso, como realizaram alterações nas construções, mobilizaram a apreensão operatória (com destaque às modificações figurais ótica e de posição); e, por terem feito uso de propriedades da Geometria Hiperbólica na resolução do problema, utilizaram a apreensão discursiva. Essa atividade é uma comprovação de que o estudo de uma das Geometrias Não-Euclidianas pode ser introduzido no ensino básico, não se resumindo apenas ao ensino superior. Ao resolver o problema proposto, os alunos atuaram na abstração geométrica hipotética (teórica).

\section{CONSIDERAÇÕES FINAIS}

Neste artigo, verificamos que, de forma significativa, as abstrações em Geometria contribuem para a compreensão do funcionamento do pensamento geométrico de estudantes do ensino básico, a partir da análise dos registros de representação semiótica. Assim, especialmente com base nos estudos de Duval (1995), realizamos a caracterização do pensamento geométrico que consiste em uma atividade específica do ser humano, sendo composto por seis abstrações geométricas hierárquicas. Logo, um aluno, ao pensar geometricamente, não aplica todas essas abstrações ao mesmo tempo. 
Desse modo, pensar geometricamente demanda a utilização de uma das seguintes abstrações em Geometria: espacial, perceptiva, analítica, descritiva, dedutiva e hipotética ou teórica. Igualmente, são essas abstrações que permitem ao aluno desenvolver essa forma de pensamento.

A seguir, no Quadro 1, apresentamos um resumo das características evidenciadas nas abstrações geométricas discutidas nesse artigo. É importante destacar que essas características foram observadas nas questões analisadas. Nesse sentido, se considerarmos outras atividades, é possível que outros atributos se manifestem.

Quadro 1 - Resumo das abstrações geométricas e características.

\begin{tabular}{|c|c|}
\hline ABSTRAÇÕES GEOMÉTRICAS & CARACTERÍSTICAS GERAIS OBSERVADAS \\
\hline Abstração Geométrica Espacial & $\begin{array}{l}\text { - Operações cognitivas: conversão (de volta) sem coordenação } \\
\text { - Apreensões geométricas: perceptiva e sequencial } \\
\text { - Olhar em Geometria: botanista } \\
\text { - Linguagem utilizada: cotidiana com caráter espacial } \\
\text { - Natureza da Geometria: prática (cotidiana) } \\
\text { - Natureza do pensamento geométrico: elementar }\end{array}$ \\
\hline Abstração Geométrica Perceptiva & $\begin{array}{l}\text { - Operações cognitivas: conversão (de ida) sem coordenação } \\
\text { - Apreensões geométricas: perceptiva e sequencial } \\
\text { - Olhar em Geometria: botanista } \\
\text { - Linguagem utilizada: cotidiana com caráter perceptivo } \\
\text { - Natureza da Geometria: prática (cotidiana) } \\
\text { - Natureza do pensamento geométrico: elementar }\end{array}$ \\
\hline Abstração Geométrica Analítica & $\begin{array}{l}\text { - Operações cognitivas: conversão (de ida) sem coordenação } \\
\text { - Apreensões geométricas: perceptiva, sequencial e discursiva (sem consistência) } \\
\text { - Olhar em Geometria: botanista } \\
\text { - Linguagem utilizada: cotidiana com caráter analítico } \\
\text { - Natureza da Geometria: prática (cotidiana) } \\
\text { - Natureza do pensamento geométrico: elementar }\end{array}$ \\
\hline Abstração Geométrica Descritiva & $\begin{array}{l}\text { - Operações cognitivas: conversão (de ida e de volta) com coordenação } \\
\text { - Apreensões geométricas: sequencial e discursiva } \\
\text { - Olhar em Geometria: agrimensor e construtor } \\
\text { - Linguagem utilizada: formal com caráter descritivo } \\
\text { - Natureza da Geometria: formal pré-dedutiva } \\
\text { - Natureza do pensamento geométrico: elementar }\end{array}$ \\
\hline Abstração Geométrica Dedutiva & $\begin{array}{l}\text { - Operações cognitivas: conversão (de ida e de volta) com coordenação e tratamento } \\
\text { - Apreensões geométricas: sequencial, discursiva e operatória (modificação mereológica) } \\
\text { - Olhar em Geometria: agrimensor e inventor } \\
\text { - Linguagem utilizada: formal argumentativa } \\
\text { - Natureza da Geometria: modelo teórico da Geometria (formal dedutiva) } \\
\text { - Natureza do pensamento geométrico: avançado }\end{array}$ \\
\hline Abstração Geométrica Hipotética & $\begin{array}{l}\text { - Operações cognitivas: conversão (de ida e de volta) com coordenação e tratamento } \\
\text { - Apreensões geométricas: sequencial, discursiva e operatória (modificações ótica e de posição) } \\
\text { - Olhar em Geometria: construtor e inventor } \\
\text { - Linguagem utilizada: formal argumentativa } \\
\text { - Natureza da Geometria: Geometrias Não-Euclidianas } \\
\text { - Natureza do pensamento geométrico: avançado }\end{array}$ \\
\hline
\end{tabular}

Fonte: Pereira da Costa (2019).

Além disso, por meio das propriedades destacadas no Quadro 1, podemos perceber que as abstrações geométricas indicam a existência de níveis de desenvolvimento do pensamento geo- 
métrico. Isso é possível verificar, pois, as características se tornam mais sofisticadas à medida que avançamos as abstrações.

Com base nas abstrações geométricas e considerando as naturezas do pensar em Geometria, construímos um esquema que apresenta um resumo da evolução do pensamento geométrico conforme nosso entendimento. Ainda, destacamos que esse esquema foi elaborado com base na estrutura do desenvolvimento cognitivo do pensamento matemático proposto por Tall (1995).

Figura 10 - Desenvolvimento do pensamento geométrico

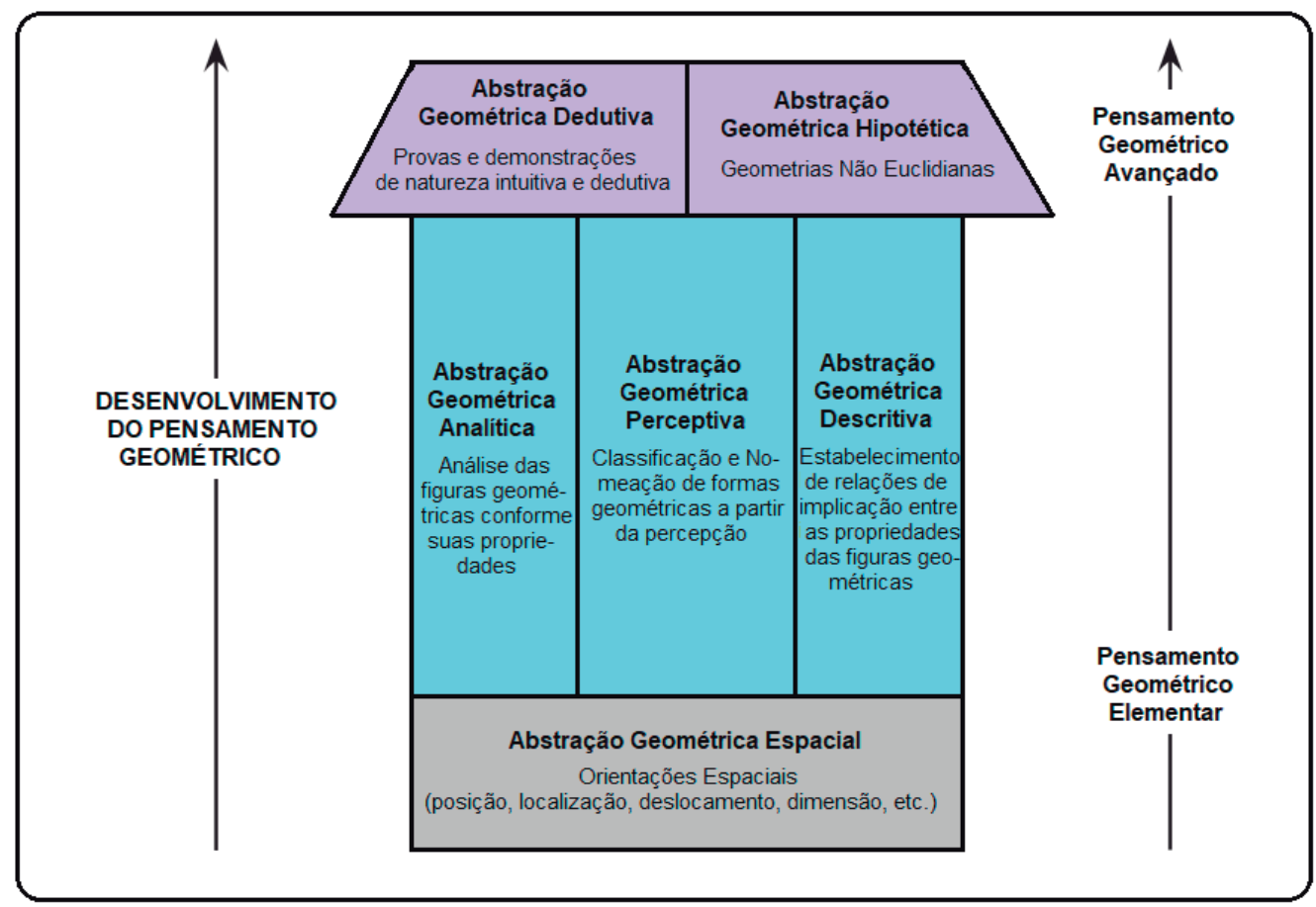

Fonte: Pereira da Costa (2019).

Realizando uma metáfora entre o desenvolvimento do pensamento geométrico com o processo de construção de uma casa, chegamos à seguinte estrutura:

- na base da casa, estão os alicerces, que correspondem à abstração geométrica espacial, por ser a base da estrutura do pensamento geométrico (a casa);

- $\quad$ as paredes são formadas pelas abstrações geométricas perceptiva, analítica e descritiva, e têm por finalidade vedar e sustentar a estrutura do pensar em Geometria;

- 0 teto é composto pelas abstrações geométricas dedutiva e hipotética, que representam a cobertura da estrutura do pensamento geométrico, estabelecendo uma ligação com os alicerces (abstração geométrica espacial) por meio das paredes (abstrações perceptiva, analítica e descritiva).

Para tanto, pensar geometricamente demanda a mobilização de, no mínimo, uma das seis abstrações geométricas aqui analisadas: a espacial, a perceptiva, a analítica, a descritiva, a dedutiva e a hipotética. Essas características emergem a partir da progressão do atributo matriz (abstração geométrica espacial). 
As outras características se desenvolvem de forma hierárquica, mas é possível 0 desenvolvimento de até duas abstrações geométricas de forma simultânea, sendo que, obrigatoriamente, uma delas é a espacial. Ainda, o progresso de uma pode impulsionar o desenvolvimento das demais.

Por fim, concluímos que há dois tipos de pensamento geométrico: elementar e avançado. 0 primeiro, dito elementar, é caracterizado pela vivência e pelo contato com a Geometria da vida prática, composta pelos objetos do mundo físico, e ainda, pelos estudos geométricos euclidianos. Já o pensamento geométrico avançado é marcado pela análise de objetos em Geometria de natureza complexa, tais como 0 estudo de processos dedutivos e a comparação de axiomáticas, entre elas, as Geometrias Não-Euclidianas. Então, é o tipo de Geometria vivenciada que possibilita o desenvolvimento do pensamento geométrico.

\section{REFERÊNCIAS}

ALMOULOUD, S. A. Fundamentos norteadores das teorias da Educação Matemática: perspectivas e diversidade. Amazônia - Revista de Educação em Ciências e Matemáticas, Belém, v. 13, n.27, p. 5-35, 2017.

BARBOSA, C. P. 0 pensamento geométrico em movimento: um estudo com professores que lecionam Matemática nos anos iniciais do Ensino Fundamental de uma escola pública de Ouro Preto (MG). 2011. Dissertação (Mestrado em Educação Matemática) - Universidade Federal de Ouro Preto, Ouro Preto, 2011.

BREDA, A.; SERRAZINA, L.; MENEZES, L.; SOUSA, H.; OLIVEIRA, P. Geometria e medida no ensino básico. Lisboa: Direção Geral de Inovação e de Desenvolvimento Curricular do Ministério da Educação de Portugal, 2011.

DUVAL, R. Sémiosis et pensée humaine: registres sémiotiques et apprentissages intellectuels. Berne: Peter Lang, 1995.

Les conditions cognitives de l'apprentissage de la géométrie: développement de la visualisation, différenciation des raisonnements et coordination de leurs fonctionnements. In: DIDACTIQUE ET SCIENCES COGNITIVES, 36., 2005, Strasbourg. Annales [...]. Strasbourg: IREM, 2005. p. 5-53.

DREYFUS, T. Advanced mathematical thinking processes. In: TALL, D. (org.), Advanced mathematical thinking. Dordrecht: Kluwer Academic Publishers, 2002. p. 25-41.

GRAVINA, M. A. Os ambientes de geometria dinâmica e o pensamento hipotético-dedutivo. 2001. Tese (Doutorado em Informática na Educação) - Universidade Federal do Rio Grande do Sul, Porto Alegre, 2001.

KLAIBER, M. A.; SOUZA, M. L.; SILVA, D. P. ; SAVIOLI, A. M. P. D. Transformações geométricas: um olhar para o processo de abstração. In: SEMINÁRIO INTERNACIONAL DE PESQUISA EM EDUCAÇÃO MATEMÁTICA, 7., Foz do Iguaçu. Anais [...]. Foz do Iguaçu: SBEM, 2018. p. 1-12.

LEIVAS, J.C.P. Imaginação, Intuição e Visualização: a riqueza de possibilidades da abordagem geométrica no currículo de cursos de Licenciatura de Matemática. 2009. Tese (Doutorado em Educação) - Universidade Federal do Paraná, Curitiba, 2009.

LEIVAS, J. C. P. ; PORTELLA, H. P. ; SOUZA, H. M. Geometrias Não-Euclidianas: uma investigação na escola básica no Brasil com utilização do Geogebra. Revista Thema, Pelotas, v. 14, n. 3, p. 210-221, 2017 
MENDES, M. F.; DELGADO, C. C. Geometria: textos de apoio para educadores de infância. Lisboa: Direção-Geral de Inovação e de Desenvolvimento Curricular do Ministério da Educação de Portugal, 2008.

MORETTI, M. T.; BRANDT, C. F. Construção de um desenho metodológico de análise semiótica e cognitiva de problemas de geometria que envolvem figuras. Educação Matemática Pesquisa, São Paulo, v. 17, n. 3, p. 597-616, 2015.

NASSER, L. 0 papel da abstração no pensamento matemático avançado. Acta Latinoamericana de Matemática Educativa, Coacalco, v. 26, n. 1, p. 889-896, 2013.

PAIS, L. C. Intuição, experiência e teoria geométrica. Revista Zetetiké, Campinas, v. 4, n. 6, p. 65-74, 1996.

PEREIRA DA COSTA, A. A construção de um modelo de níveis de desenvolvimento do pensamento geométrico: o caso dos quadriláteros notáveis. 2019. Tese (Doutorado em Educação Matemática e Tecnológica) - Universidade Federal de Pernambuco, Recife, 2019.

PIRES, C. M. C.; CURI, E.; CAMPOS, T. M. M. Espaço e forma: a construção geométrica pelas crianças das quatro séries iniciais do Ensino Fundamental. São Paulo: PROEM, 2000.

RÉGNIER, J.C. Análise Estatística Implicativa. Curso Ofertado à Universidade Federal Rural de Pernambuco - UFRPE, Recife, 2017.

SANTOS COSTA, M.; ALLEVATO, N. S. G.; MOURA, A. R. L. Ensino-aprendizagem de orientação espacial e deslocamento nos anos iniciais do ensino fundamental: modos diferentes de ver pela pesquisa. Vidya, Santa Maria, v. 37, n. 1, p. 19-34, 2017.

THÉRĖSE, G. Quelques instruments de pensée en géométrie. MATH-ÉCOLE, Neufchâtel, v. 1, n. 193, 2000. p. 1-10.

TALL, D. Cognitive Growth in Elementary and Advanced Mathematical Thinking. In: CONFERENCE OF THE INTERNATIONAL GROUP FOR THE PSYCHOLOGY OF LEARNING MATHEMATICS, 1., 1995, Recife. Anais [...]. Recife: UFPE, 1995, p. 161-175.

TRIVIÑOS, A. N. S. Introdução à pesquisa em Ciências Sociais: a pesquisa qualitativa em Educação. São Paulo: Atlas, 1987.

RECEBIDO EM: 19 set. 2019

CONCLUÍDO EM: 30 mar. 2020 